Cite this: Org. Biomol. Chem., 2014, 12,1203

Received 21st November 2013, Accepted 23rd December 2013

DOI: $10.1039 / c 30 b 42306 a$

www.rsc.org/obc

\section{Huisgen-based conjugation of water-soluble porphyrins to deprotected sugars: towards mild strategies for the labelling of glycans $\uparrow$}

\author{
Francesca Giuntini, $t^{\mathrm{a}}$ Francesca Bryden, ${ }^{a}$ Robin Daly, ${ }^{\mathrm{b}}$ Eoin M. Scanlan ${ }^{\mathrm{b}}$ and \\ Ross W. Boyle*a
}

\begin{abstract}
Fully deprotected alkynyl-functionalised mono- and oligosaccharides undergo CuAAC-based conjugation with water-soluble porphyrin azides in aqueous environments. The mild reaction conditions are fully compatible with the presence of labile glycosidic bonds. This approach provides an ideal strategy to conjugate tetrapyrroles to complex carbohydrates.
\end{abstract}

\section{Introduction}

Advances in the field of functional glycomics shed light on the structural and functional diversity of carbohydrates exposed on the cell membrane, and their fundamental role in a variety of biological processes, including protein folding, self-recognition, cell migration, modulation of signalling pathways, and trafficking. ${ }^{1,2}$ The weak but highly specific binding of surfaceexposed glycans with carbohydrate-binding proteins (e.g. lectins) underpins diverse phenomena such as immune system modulation, pathogen invasion, cell migration and proliferation. Variations in the structure, expression, or binding affinity of glycans and glycoproteins have been associated with the state and invasiveness of neoplastic lesions ${ }^{3,4}$ and nonmalignant diseases, ${ }^{5}$ and with bacterial virulence and invasion of host tissues, ${ }^{6,7}$ as a consequence, the biochemistry of glycan-lectin interactions has been object of investigation as a potential route for the identification of new therapeutic targets, and the development of expeditious diagnostic methods. ${ }^{8-11}$

Recently, the possibility of exploiting glycan-lectin interactions for analytical and sensing purposes has also received a great deal of attention, with a consistent body of data

\footnotetext{
${ }^{a}$ Department of Chemistry, University of Hull, Kingston-upon-Hull, East Yorkshire HU6 7RX, UK. E-mail: R.W.Boyle@hull.ac.uk

${ }^{b}$ School of Chemistry, Trinity Biomedical Sciences Institute, Trinity College, 152-160 Pearse Street, Dublin 2, Ireland

$\dagger$ Electronic supplementary information (ESI) available. See DOI: 10.1039/c3ob42306a

$\$$ Present address: School of Pharmacy and Biomolecular Sciences, Liverpool John Moores University, Liverpool L3 3AF, UK.
}

demonstrating how viruses, bacterial strains, and bacterial spores can be detected by exploiting the specificity of glycanlectin interactions. Many high-throughput strategies to probe glycan-lectin interactions have been devised, the majority of which are based on fluorescence-assisted arrays, renewing the interest in the synthesis of fluorescently labelled glycans and lectins. ${ }^{12-17}$ While labelling of proteins is readily achievable, the derivatisation of glycans remains less explored. The complex structure of glycans and the recurring presence of labile moieties (e.g. sialic acid) ${ }^{18}$ pose a challenge to their chemical modification, and although various labelling strategies have been reported, a versatile and reliable approach remains to be devised. ${ }^{13,19,20}$

Following our current interest in mild bio-orthogonal approaches for the conjugation of tetrapyrrolic photosensitisers to macromolecules, ${ }^{21-24}$ we undertook a study aimed at identifying a suitable method for the conjugation of porphyrins to glycans. A straightforward ligation strategy to label glycans with porphyrins would not merely afford new luminescent lectin markers for in vitro assays, but could lead to phototherapeutic agents targeted to cells over-expressing lectins, to viruses, and to bacteria organised in biofilms. Mannose containing glycopeptides labelled with fluorescein have previously been used in cellular immunology screens for the development of carbohydrate vaccines. ${ }^{25}$ Endowed with high absorption coefficients and high luminescence and singlet oxygen quantum yields, porphyrins have found a variety of applications in the biomedical field. ${ }^{26}$ Their versatility towards chemical modification, which allows the tuning of the molecule's physico-chemical properties, contributed to make these species excellent candidates as photodynamic therapy drugs, reporters for fluorescent diagnosis, and investigative tools.

The association of porphyrins with carbohydrates has been widely explored with the purpose of obtaining water-soluble or targeted species. ${ }^{27}$ The synthesis of porphyrin-carbohydrate conjugates is however hampered by their conflicting solubility, which often imposes the use of solvent mixtures, high temperatures, or alternatively requires the use of protected carbohydrates. ${ }^{28-34}$ 
While these approaches prove efficient for the synthesis of porphyrin-monosaccharides conjugates, mild methods that preserve the integrity of labile polysaccharides remain substantially unavailable.

In a previous study ${ }^{23}$ we showed that water-soluble porphyrin-azides can be conjugated to polyacrylamide nanoparticles in aqueous environment and in mild conditions, by copper-catalysed azide-alkyne cycloaddition (CuAAC). ${ }^{35,36}$ We reasoned that, in a similar way, CuAAC could provide the optimal ligation chemistry for conjugation of porphyrins to glycans. CuAAC has proved to be an efficient tool for the conjugation of porphyrins to peptides, ${ }^{37}$ polymers, and carbohydrates; $;^{30,32,34,38}$ furthermore, as a result of intense investigations recently carried out in the field, the feasibility of this approach is facilitated by the improved synthetic accessibility of azide-containing porphyrins $s^{22,23,39}$ and alkynylcarbohydrates. ${ }^{40}$

We first assessed the efficiency of the cycloaddition using water-soluble porphyrin $\mathbf{1}$ and a simple deprotected monosaccharide bearing a terminal alkyne. Porphyrin 1 was synthesised from 5-(4-aminophenyl)-10,15,20-triphenylporphyrin, which was converted into the corresponding azide by treatment with sodium nitrite and sodium azide in water, according to a modified literature procedure. ${ }^{39}$ The resulting porphyrin-azide was treated with iodomethane, to afford the water-soluble tricationic species. In order to avoid sequestration of copper ions by the tetrapyrrole during the cycloaddition, the porphyrin free base were converted into the corresponding zinc complex. ${ }^{23}$

Treatment of an aqueous solution of porphyrin 1 with 1- $\alpha$-propargyloxy mannose $4^{39}$ in the presence of $\mathrm{CuSO}_{4} \cdot 5 \mathrm{H}_{2} \mathrm{O}$ and sodium ascorbate at room temperature, led to the complete conversion of $\mathbf{1}$ into cycloadduct $\mathbf{1 1}$ within 15 minutes. (Scheme 1, Table 1).

Isolation of the desired product from the reaction mixture was achieved by treating the reaction mixture with $\mathrm{NH}_{4} \mathrm{PF}_{6}$, which allowed the recovery of the water-insoluble hexafluorophosphate salt of the porphyrin by filtration, and subsequent conversion of the hexachlorophosphate salt into the corresponding trichloride by treatment of with tetra- $n$-butylammonium chloride in acetone. ${ }^{23}$

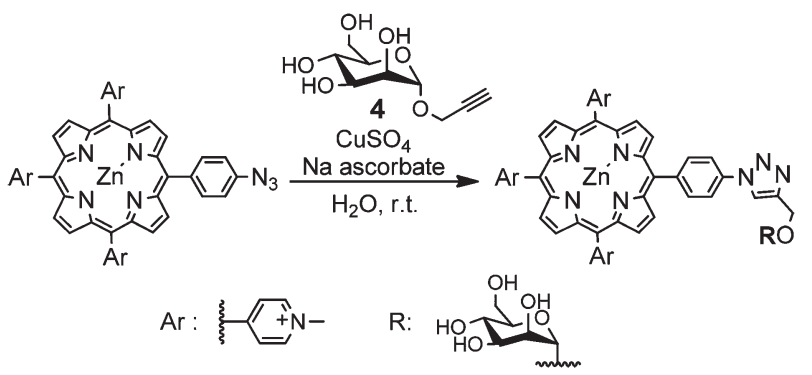

Scheme 1 CuAAC conjugation of porphyrin-azide 1 to 1 - $\alpha$-propargylmannose. Reaction conditions: 1 (1 equiv.), 4 (1.5 equiv.), $\mathrm{CuSO}_{4} \cdot 5 \mathrm{H}_{2} \mathrm{O}$ ( 0.2 equiv.), $\mathrm{Na}$ ascorbate ( 0.5 equiv.), room temperature, $15 \mathrm{~min}$.
Table 1 Synthetic scope of the CuAAC-based cycloaddition: reaction of porphyrin-azides with 1-propargyloxy-monosaccharides
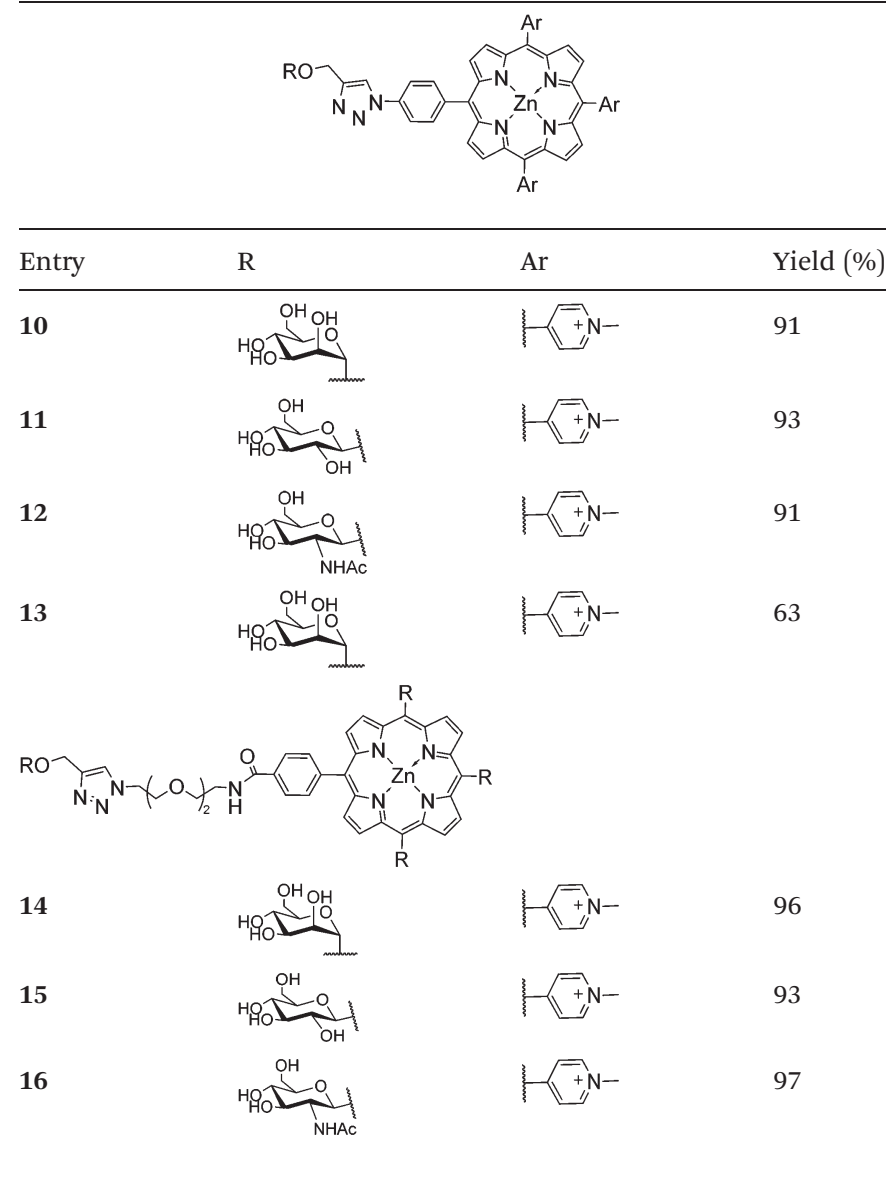

Encouraged by this positive result, we investigated the applicability of the conjugation to different deprotected carbohydrate and porphyrin substrates (Fig. 1). Gratifyingly, 1- $\beta$-propargyloxymonosaccharides 5 and $\mathbf{6}$ and 1- $\beta$-propargyloxy- $N$-acetyllactosamine 7 underwent CuAAC with 1 to afford, respectively, adducts 10, 12 and 17 in excellent yields, and negatively charged porphyrin 4 reacted with 1- $\alpha$-propargyloxy mannose 4 under the conditions described above, to afford the desired conjugates in equally good yield (Table 1). Similarly, the presence of a PEG chain as a spacer between the porphyrin and the azide group did not affect the conjugation efficiency, as shown by the formation of cycloadducts 14-16 in high yields from the reaction of porphyrin 3 with 1- $\alpha$-propargyloxy-hexoses 4-6. ${ }^{39}$ The excellent yields indicate that our approach has the potential of becoming a reliable bioconjugation tool of general applicability.

We next proceeded to verify the compatibility of the ligation conditions with the presence of labile glycosidic bonds: we chose propargyloxy-bearing $\alpha$-Fuc-(1-6)-GlcNAc 8 and Lewis ${ }^{x}$ trisaccharide $\mathbf{9}^{41}$ as models for a glycan substrate, as the link $\alpha-(1-6)$ is known to be unstable to acidic and basic conditions, and high temperatures. When porphyrin 1 was treated with 8 or 9 under the conditions reported above, the desired cycloadducts were isolated (Table 2), and the spectroscopic data 

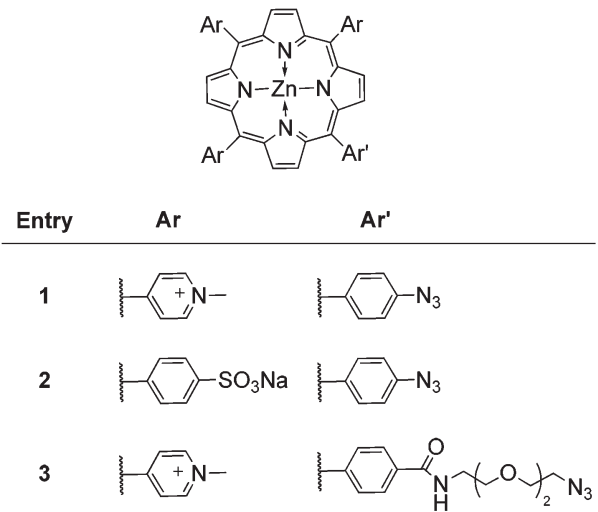
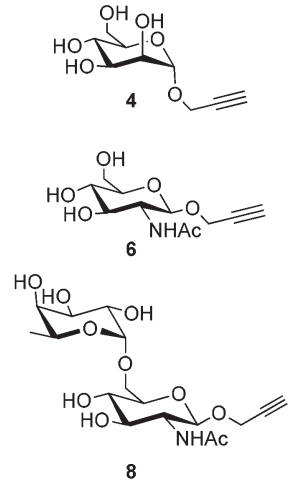
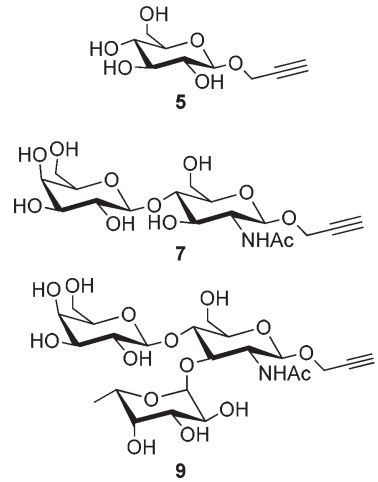

Fig. 1 Porphyrin azides and propargyloxy sugars employed in the cycloadditions. Cationic porphyrins 1 and 3 are used as the trichlorides.

Table 2 Synthetic scope of the CuAAC-based cycloaddition: reaction of porphyrin-azides to oligosaccharides

19

confirmed that the oligosaccharide moieties were intact in both 18 and 19. To the best of our knowledge, this is the first report of the conjugation of a porphyrin to a totally deprotected $\alpha$-Fuc-(1-6)-GlcNAc and Lewis ${ }^{\mathrm{x}}$ trisaccharide; the integrity of the labile link $\alpha-(1-6)$ in the conjugates further confirms the suitability this of ligation method for glycan labelling.

\section{Conclusions}

In conclusions, we devised a CuAAC-based method for the ligation of water-soluble azide-bearing porphyrins to alkynebearing fully deprotected carbohydrates. The reaction takes place in aqueous solution and affords the desired conjugates in good-to-excellent yields, and involves minimal manipulation for the isolation of the cycloaddition product. Variations of the structure of the carbohydrate and of the porphyrin are well tolerated and do not impair the efficiency of the reaction. Ligation of porphyrins to totally deprotected carbohydrates containing the labile $\alpha-(1-6)$ glycosidic bond, a recurrent feature in the structure of glycans, are achievable with this method. It is envisaged that this approach will complement the recent chemo-enzymatic strategies for glycan modification. ${ }^{42}$ Although it did not represent an issue in the present work, the presence of the copper ion is certainly a caveat for any CuAACbased labelling strategy to be carried out in biological environment: we anticipate that the new porphyrins reported here will be equally reactive under copper-free conditions, ${ }^{43}$ which has already been successfully applied to cyclooctyne-functionalised carbohydrate substrates. ${ }^{44}$ The application of this approach to more complex carbohydrates is the object of current studies in our laboratories.

\section{Acknowledgements}

The authors thank EPSRC for funding the project (EP/ H000151/1). Mass spectrometry data was acquired at the EPSRC UK National Mass Spectrometry Facility at Swansea University.

\section{Notes and references}

$1 \mathrm{~J} . \mathrm{Li}$ and J. Richards, in Functional Glycomics, ed. J. Li, Humana Press, 2010, vol. 600, pp. 1-8.

2 G. W. Hart and R. J. Copeland, Cell, 2010, 143, 672-676.

3 C. Slawson and G. W. Hart, Nat. Rev. Cancer, 2011, 11, 678684.

4 N. D. S. Rambaruth and M. V. Dwek, Acta Histochem., 2011, 113, 591-600.

5 A. Kuno, Y. Ikehara, Y. Tanaka, T. Angata, S. Unno, M. Sogabe, H. Ozaki, K. Ito, J. Hirabayashi, M. Mizokami and H. Narimatsu, Clin. Chem., 2011, 57, 48-56. 
6 G. A. Rabinovich and M. A. Toscano, Nat. Rev. Immunol., 2009, 9, 338-352.

7 R. C. Davicino, R. J. Eliçabe, M. S. Di Genaro and G. A. Rabinovich, Int. Immunopharmacol., 2011, 11, 14571463.

8 J. Katrlík, J. Švitel, P. Gemeiner, T. Kožár and J. Tkac, Med. Res. Rev., 2010, 30, 394-418.

9 A. Bernardi, J. Jimenez-Barbero, A. Casnati, C. De Castro, T. Darbre, F. Fieschi, J. Finne, H. Funken, K.-E. Jaeger, M. Lahmann, T. K. Lindhorst, M. Marradi, P. Messner, A. Molinaro, P. V. Murphy, C. Nativi, S. Oscarson, S. Penades, F. Peri, R. J. Pieters, O. Renaudet, J.-L. Reymond, B. Richichi, J. Rojo, F. Sansone, C. Schaffer, W. B. Turnbull, T. Velasco-Torrijos, S. Vidal, S. Vincent, T. Wennekes, H. Zuilhof and A. Imberty, Chem. Soc. Rev., 2013, 42, 4709-4727.

10 H. An and C. Lebrilla, in Functional Glycomics, ed. J. Li, Humana Press, 2010, vol. 600, pp. 199-213.

11 D. H. Dube and C. R. Bertozzi, Nat. Rev. Drug Discovery, 2005, 4, 477-488.

12 D. Grünstein, M. Maglinao, R. Kikkeri, M. Collot, K. Barylyuk, B. Lepenies, F. Kamena, R. Zenobi and P. H. Seeberger, J. Am. Chem. Soc., 2011, 133, 13957-13966.

13 X. Song, Y. Lasanajak, B. Xia, D. F. Smith and R. D. Cummings, ACS Chem. Biol., 2009, 4, 741-750.

14 S. Park, J.-W. Sung and I. Shin, ACS Chem. Biol., 2009, 4, 699-701.

15 X. Song, J. Heimburg-Molinaro, N. Dahms, D. Smith and R. Cummings, in Carbohydrate Microarrays, ed. Y. Chevolot, Humana Press, 2012, vol. 808, pp. 137-148.

16 X. Wang, O. Ramstrom and M. Yan, Chem. Commun., 2011, 47, 4261-4263.

17 X. Song, B. Xia, S. R. Stowell, Y. Lasanajak, D. F. Smith and R. D. Cummings, Chem. Biol., 2009, 16, 36-47.

18 C. R. Bertozzi and L. L. Kiessling, Science, 2001, 291, 23572364 .

19 K. W. Dehnert, B. J. Beahm, T. T. Huynh, J. M. Baskin, S. T. Laughlin, W. Wang, P. Wu, S. L. Amacher and C. R. Bertozzi, ACS Chem. Biol., 2011, 6, 547-552.

20 L. R. Ruhaak, G. Zauner, C. Huhn, C. Bruggink, A. M. Deelder and M. Wuhrer, Anal. Bioanal. Chem., 2010, 397, 3457-3481.

21 C. M. A. Alonso, A. Palumbo, A. J. Bullous, F. Pretto, D. Neri and R. W. Boyle, Bioconjugate Chem., 2010, 21, 302-313.

22 F. Bryden and R. W. Boyle, Synlett, 2013, 1978-1982.

23 F. Giuntini, F. Dumoulin, R. Daly, V. Ahsen, E. M. Scanlan, A. S. P. Lavado, J. W. Aylott, G. A. Rosser, A. Beeby and R. W. Boyle, Nanoscale, 2012, 4, 2034-2045.

24 R. Hudson, M. Carcenac, K. Smith, L. Madden, O. J. Clarke, A. Pelegrin, J. Greenman and R. W. Boyle, Br. J. Cancer, 2005, 92, 1442-1449.
25 M. A. Brimble, R. Kowalczyk, P. W. R. Harris, P. R. Dunbar and V. J. Muir, Org. Biomol. Chem., 2008, 6, 112-121.

26 R. K. Pandey and G. Zheng, in The Porphyrin Handbook, ed. K. M. Kadish, K. M. Smith and R. Guilard, Academic Press, London, 2000, vol. 6, pp. 157-230.

27 X. Zheng and R. K. Pandey, Anti-Cancer Agents Med. Chem., 2008, 8, 241-268.

28 J. P. C. Tomé, E. M. P. Silva, A. M. V. M. Pereira, C. M. A. Alonso, M. A. F. Faustino, M. G. P. M. S. Neves, A. C. Tomé, J. A. S. Cavaleiro, S. A. P. Tavares, R. R. Duarte, M. F. Caeiro and M. L. Valdeira, Bioorg. Med. Chem., 2007, 15, 4705-4713.

29 R. Daly, G. Vaz, A. M. Davies, M. O. Senge and E. M. Scanlan, Chem.-Eur. J., 2012, 18, 14671-14679.

30 G. Garcia, D. Naud-Martin, D. Carrez, A. Croisy and P. Maillard, Tetrahedron, 2011, 67, 4924-4932.

31 D. Kushwaha and V. K. Tiwari, J. Org. Chem., 2013, 78, 8184-8190.

32 S. v. Ballut, D. Naud-Martin, B. Loock and P. Maillard, J. Org. Chem., 2011, 76, 2010-2028.

33 S. Achelle, P. Couleaud, P. Baldeck, M.-P. Teulade-Fichou and P. Maillard, Eur. J. Org. Chem., 2011, 1271-1279.

34 M. G. H. Vicente, E. Hao and T. J. Jensen, J. Porphyrins Phthalocyanines, 2009, 13, 51-59.

35 V. V. Rostovtsev, L. G. Green, V. V. Fokin and K. B. Sharpless, Angew. Chem., Int. Ed., 2002, 41, 25962599.

36 C. W. Tornøe, C. Christensen and M. Meldal, J. Org. Chem., 2002, 67, 3057-3064.

37 F. Giuntini, C. M. A. Alonso and R. W. Boyle, Photochem. Photobiol. Sci., 2011, 10, 759-791.

38 B. L. Carpenter, E. Feese, H. Sadeghifar, D. S. Argyropoulos and R. A. Ghiladi, Photochem. Photobiol., 2012, 88, 527-536.

39 O. B. Locos, C. C. Heindl, A. Corral, M. O. Senge and E. M. Scanlan, Eur. J. Org. Chem., 2010, 1026-1028.

40 P. H. Seeberger, N. Finney, D. Rabuka and C. R. Bertozzi, in Essential of Glycobiology, ed. A. Varki, R. D. Cummings, J. D. Esko, H. H. Freeze, P. Stanley, C. R. Bertozzi, G. W. Hart and M. E. Etzeler, Cold Spring Harbor Laboratory Press, Cold Spring Harbor, 2nd edn, 2009, pp. 691-703.

41 R. Daly, T. McCabe and E. M. Scanlan, J. Org. Chem., 2012, 78, 1080-1090.

42 E. Boeggeman, B. Ramakrishnan, M. Pasek, M. Manzoni, A. Puri, K. H. Loomis, T. J. Waybright and P. K. Qasba, Bioconjugate Chem., 2009, 20, 1228-1236.

43 P. V. Chang, J. A. Prescher, E. M. Sletten, J. M. Baskin, I. A. Miller, N. J. Agard, A. Lo and C. R. Bertozzi, Proc. Natl. Acad. Sci. U. S. A., 2010, 107, 1821-1826.

44 I. Singh, C. Freeman, A. Madder, J. S. Vyle and F. Heaney, Org. Biomol. Chem., 2012, 10, 6633-6639. 